\title{
Comparative effectiveness of surgical versus nonoperative management of unilateral, nondisplaced, subaxial cervical spine facet fractures without evidence of spinal cord injury
}

\author{
Bizhan Aarabi \\ Stuart Mirvis \\ Kathirkamanthan Shanmuganathan \\ Cassandra J. Holmes \\ College of William and Mary
}

\section{Recommended Citation}

Aarabi, B., Mirvis, S., Shanmuganathan, K., Vaccaro, A. R., Holmes, C. J., Akhtar-Danesh, N., ... \& Dvorak, M. F. (2014). Comparative effectiveness of surgical versus nonoperative management of unilateral, nondisplaced, subaxial cervical spine facet fractures without evidence of spinal cord injury. Journal of Neurosurgery: Spine, 20(3), 270-277. 


\title{
Comparative effectiveness of surgical versus nonoperative management of unilateral, nondisplaced, subaxial cervical spine facet fractures without evidence of spinal cord injury
}

\author{
Clinical article
}

\author{
Bizhan Aarabi, M.D., F.R.C.S.C., ${ }^{1}$ Stuart Mirvis, M.D., ${ }^{2}$ \\ Kathirkamanthan Shanmuganathan, M.D., ${ }^{2}$ Alexander R. Vaccaro, M.D., Ph.D., ${ }^{3}$ \\ Cassandra J. Holmes, ${ }^{4}$ Noori Akhtar-Danesh, Ph.D., 5 \\ Michael G. Fehlings, M.D., Ph.D., F.R.C.S.C., ${ }^{6}$ \\ and Marcel F. DvoraK, M.D., F.R.C.S.C. ${ }^{7}$ \\ Departments of ${ }^{1}$ Neurosurgery and ${ }^{2}$ Radiology, University of Maryland School of Medicine, Baltimore, \\ Maryland; ${ }^{3}$ Department of Orthopedic Surgery, Thomas Jefferson University, Philadelphia, Pennsylvania; \\ ${ }^{4}$ College of William and Mary, Williamsburg, Virginia; ${ }^{5}$ Department of Clinical Epidemiology and \\ Biostatistics, and Department of Math and Statistics, McMaster University, Hamilton, Ontario; ${ }^{6}$ Department \\ of Neurosurgery, University of Toronto, Ontario; and ${ }^{7}$ Department of Orthopaedics, University of British \\ Columbia, Vancouver, British Columbia, Canada
}

\begin{abstract}
Object. Facet joints are major stabilizers of cervical motion allowing for effortless and pain-free multidimensional cervical spine movements without significant linear or rotational translation, thus minimizing any chance for spinal cord or nerve root impingement. Unilateral, nondisplaced subaxial facet fractures do not meet the conventional criteria for spinal instability under physiological loads. Limited evidence indicates that even with no or minimal displacement, $20 \%-80 \%$ of these fractures fail nonoperative management. The risk factors for instability in isolated nondisplaced subaxial facet fractures remain uncertain. In this retrospective study of prospectively collected data, the authors attempted to identify the predictors of failure in the management of isolated, nondisplaced subaxial facet fractures admitted to their Level I trauma center over a 10-year period.

Methods. Demographic, clinical, imaging, and follow-up data for 25 patients with unilateral nondisplaced subaxial facet fractures who were managed surgically $(n=10)$ or nonoperatively $(n=15)$ were statistically analyzed.

Results. The mean age of the patients was 38 years, 19 were male, and 21 of the fractures were the result of either motor vehicle accidents or falls. The mean motor score on the American Spinal Injury Association scale was 99.2, and the mean Subaxial Injury Classification (SLIC) severity score was 3 (operated 3.5, nonoperated 2.3). Allen mechanistic classification included 22 compressive-extension Stage 1 and 2 distractive-extension Stage 1 fractures. Subaxial facet fractures involved C-7 in 17 patients (68\%), C-6 in 7 (28\%), and C-3 in 1 (4\%). The anatomical plane of fracture through the lateral mass was sagittal in 12 patients, axial in 8 , and coronal in 3 patients. Nondisplaced floating lateral mass injuries were noted in 2 patients. The mean instability score, considering 7 components of the discoligamentous complex on MRI, was 3.2 (operated 3.6, nonoperated 3.0). Ten (40\%) of 25 patients in this investigation did not have successful management, 9 in the nonoperated and 1 in the operated group $(\mathrm{p}=0.018)$. Unsuccessful management was significantly greater in younger patients $(\mathrm{p}=0.0008)$, possibly indicating selection bias $(\mathrm{p}=0.07$, Wilcoxon ranksum test). Fracture plane, instability, and SLIC scores did not play a significant role in treatment failure in this study.

Conclusions. In this study, surgery was superior to nonoperative management of isolated, nondisplaced, or minimally displaced subaxial cervical spine facet fractures.
\end{abstract} (http://thejns.org/doi/abs/10.3171/2013.11.SPINE13733)

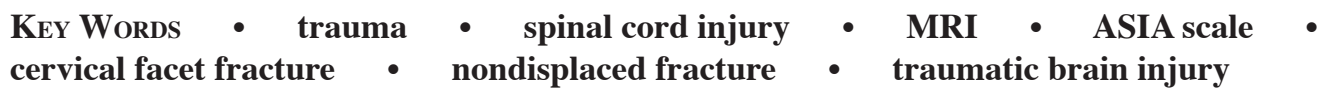

$\mathrm{O}$ $\mathrm{NE}$ of the fundamental uncertainties about traumatic fracture dislocations of the vertebral column is the degree of instability. The concept of instabil-

Abbreviations used in this paper: ASIA = American Spinal Injury Association; GCS = Glasgow Coma Scale; SLIC = Subaxial Injury Classification. ity was first proposed by Nicoll ${ }^{14}$ and was expanded by Holdsworth's suggestion that the discoligamentous complex was vital in securing stability of the human vertebral column. ${ }^{10}$ Multiple subaxial cervical spine injury classification systems and checklists have assigned descriptive or numerical value to stability, aimed at assisting health care providers in surgical or nonoperative management of cer- 


\section{Management of unilateral nondisplaced subaxial facet fractures}

vical spine fracture dislocations. ${ }^{1,2,6,9,20,21}$ Facet joints and their capsules are major stabilizers of subaxial cervical spine motion segments, facilitating pain-free movements of the cervical spine under physiological loads without compromising the spinal cord or nerve roots. ${ }^{21,22}$ While a significant proportion of subaxial fracture dislocations are associated with a fractured lateral mass or its articulating processes, less than $5 \%$ of all symptomatic cervical spine injuries are isolated nondisplaced facet fractures without spinal cord injury. ${ }^{3,4,7,18}$ According to the checklist criteria of White et al. or the scales developed by Anderson et al. and Vaccaro et al., patients with unilateral, nondisplaced lateral mass/facet fractures would not be directed to surgical intervention; however, nonoperative management is unsuccessful in $20 \%-80 \%$ of these patients. $2,4,7,8,12,13,20,21$ In this study we sought to define predictors of instability in isolated, nondisplaced, or minimally displaced cervical spine facet fractures without any evidence of spinal cord injury. The null hypothesis was that surgical and nonoperative management are equally efficient in achieving longterm stability of unilateral nondisplaced or minimally displaced isolated subaxial facet fractures.

\section{Methods}

\section{Study Design}

Facet fractures are defined as fractures involving the cervical spine lateral mass or its articulating processes. The plane of the fracture could be axial (Fig. 1), sagittal (Fig. 2), coronal (Fig. 3), or floating lateral mass (Fig. 4). The specific aim of this ambispective study (retrospective study of prospectively collected data) was to determine if nonoperative management is as effective as internal fixation in securing stability and long-term anatomical align- ment of the subaxial cervical spine after isolated nondisplaced or minimally displaced facet fractures.

The inclusion criteria were the presence of: 1) isolated nondisplaced or minimally displaced $(<3 \mathrm{~mm}) \mathrm{sub}-$ axial lateral mass fractures, 2) radicular irritation or dysfunction, and 3) indeterminate discoligamentous injury. The exclusion criteria were: 1) any evidence of subluxation of vertebral bodies of the related motion segment; 2) evidence of spinal cord injury; 3 ) bilateral or multilevel facet injuries; 4) fractures of the vertebral body; 5) ankylosing spondylitis or diffuse idiopathic skeletal hyperostosis; and 6) definite discoligamentous injury as noted on MRI. The study was approved by the Institutional Review Board of the University of Maryland School of Medicine.

\section{Patient Characteristics}

From January 1, 2001, through December 31, 2011, 1335 patients with symptomatic cervical spine injuries were admitted to our Level I trauma center. Of these patients, $25(2 \%)$ had isolated nondisplaced subaxial facet/ lateral mass fractures. Table 1 lists the clinical characteristics of these patients. A symptom composite of pain, paresthesia, and weakness, or any combination, was prevalent among patients with isolated, nondisplaced facet fractures. Seventeen $(68 \%)$ of the 25 patients complained of mild to severe pain. The pain perception was at the level of the neck, shoulder, arm, or chest. Fourteen patients (56\%) complained of paresthesia, usually along a specific nerve root. Ten patients (40\%) complained of muscle weakness. Evidence of multiple injuries was observed in 13 patients (52\%): internal carotid and vertebral arteries in 5 patients, traumatic brain injury in 6, pulmonary in 3, and metatarsal fracture and liver laceration in 1 patient each. The Glasgow Coma Scale (GCS) score was 13-15 in 21 patients, 9-12 in 1 patient, and 6-8 in 3 patients.
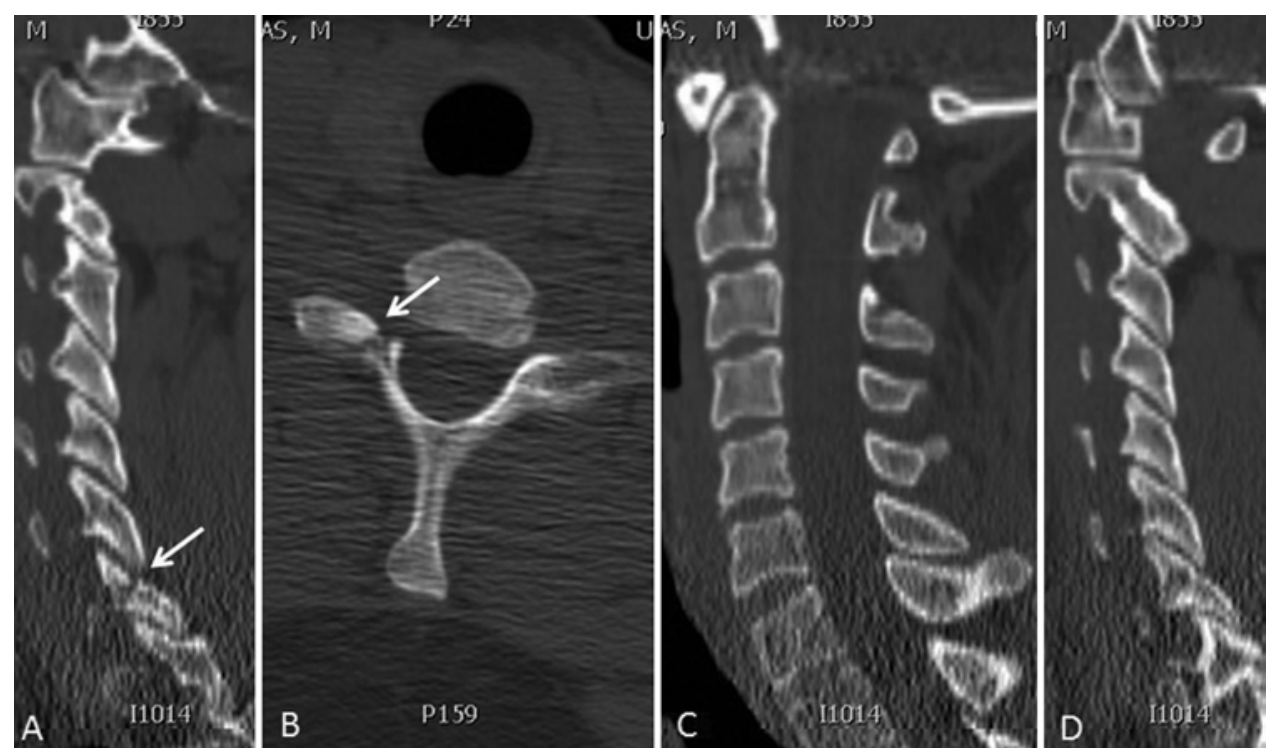

Fig. 1. Sagittal (A, C, and D) and axial (B) CT scans of a cervical spine from a 40-year-old male patient who was admitted to the trauma center with neck and arm pain following a body surfing accident. He was fully conscious but manifested 4/5 weakness of his right triceps muscle. The CT scans indicate an axial-type fracture of the superior articulating process of C-7 on the right side (arrows). His SLIC score was 5 and MRI of the cervical spine indicated an instability score of 3.8. This patient underwent posterior spinal fusion of 1 motion segment (C6-7). 
B. Aarabi et al.
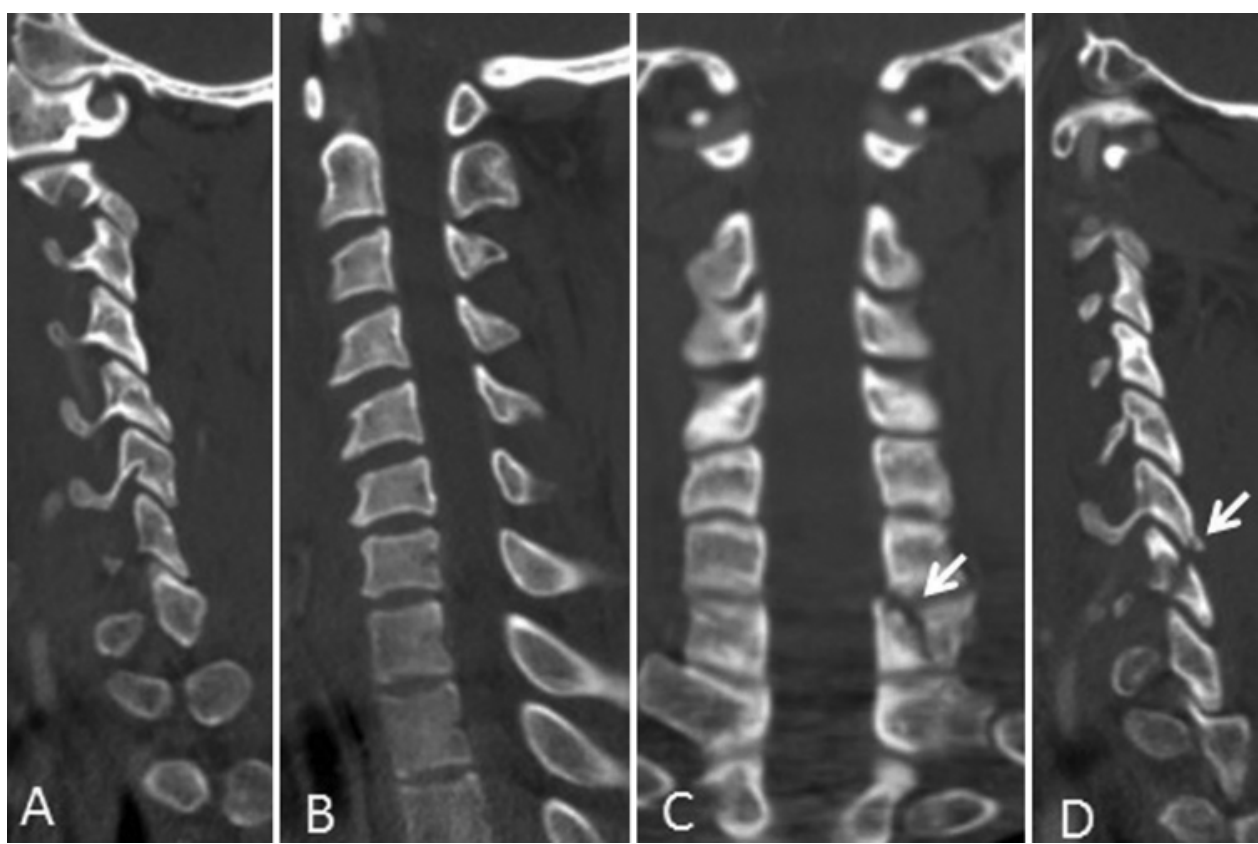

FIG. 2. Sagittal (A, B and D) and coronal (C) CT scans of a cervical spine from a 19-year-old male patient who was admitted to the trauma center with neck pain following a motor vehicle accident. He was fully conscious but had Grade $2 / 5$ weakness of his left triceps. The CT scans show a sagittal fracture through the C-7 lateral mass on the left side (arrows). His SLIC score was 3 and his instability score was 1.7. He was treated with a Halo vest device and successful fusion 3 months after his injury.

\section{Imaging Studies}

All patients underwent CT, and all but 2 patients had MRI of the cervical spine. The perceived mechanism of injury based on CT scans, with application of the Allen classification, was extension (compressive or distractive) in all cases except 1 ; in the latter case, the mechanism was distractive-flexion injury. ${ }^{1}$ The primary investigator and 2 blinded radiologists classified the fracture morphology and the severity of injury to the discoligamentous complex (Figs. 1-4; Table 1). Fracture was at the level of the
C-6 and C-7 vertebrae in 24 patients (96\%). We used MRI to confirm a lack of spinal cord injury and to grade the level of injury severity to 7 ligaments of the cervical spine discoligamentous complex (anterior longitudinal ligament/anterior annulus, disc, posterior annulus/posterior longitudinal ligament, ligamentum flavum, joint capsule on right side, joint capsule on left side, and interspinous ligament) ${ }^{17}$ Injury severity score for a specific ligament was 0 if the ligament was intact, 0.5 if the injury was indeterminate, and 1 if the ligament was completely disrupted. For all 7 ligaments, the scores ranged from 0 to 7.
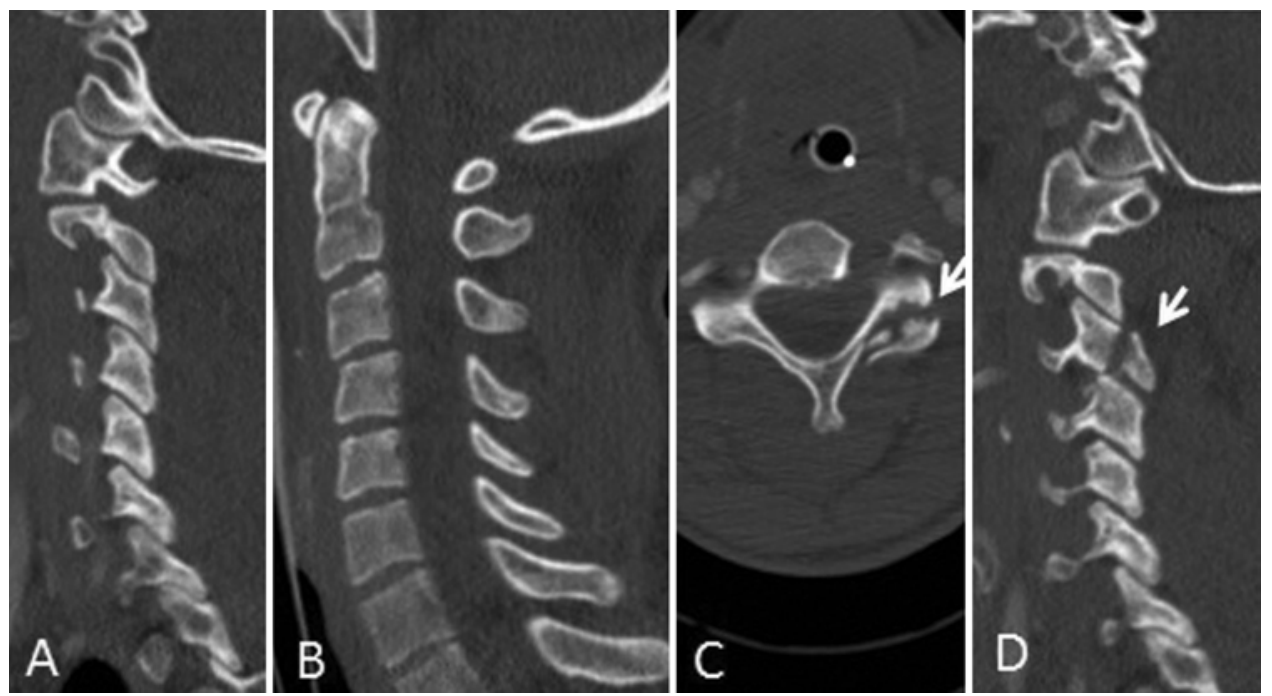

Fig. 3. Sagittal (A, B, and D) and axial (C) CT scans of the cervical spine in a 19-year-old male patient who was admitted to the trauma center following a motor vehicle accident. His GCS score was 10 (motor score 6) and his motor examination was not testable. These CT scans indicate a coronal fracture through the lateral mass of C-3 on the left side (arrows). This patient had an SLIC score of 5 and an instability score of 4.8 . He was successfully treated using a Halo vest device for 3 months. 

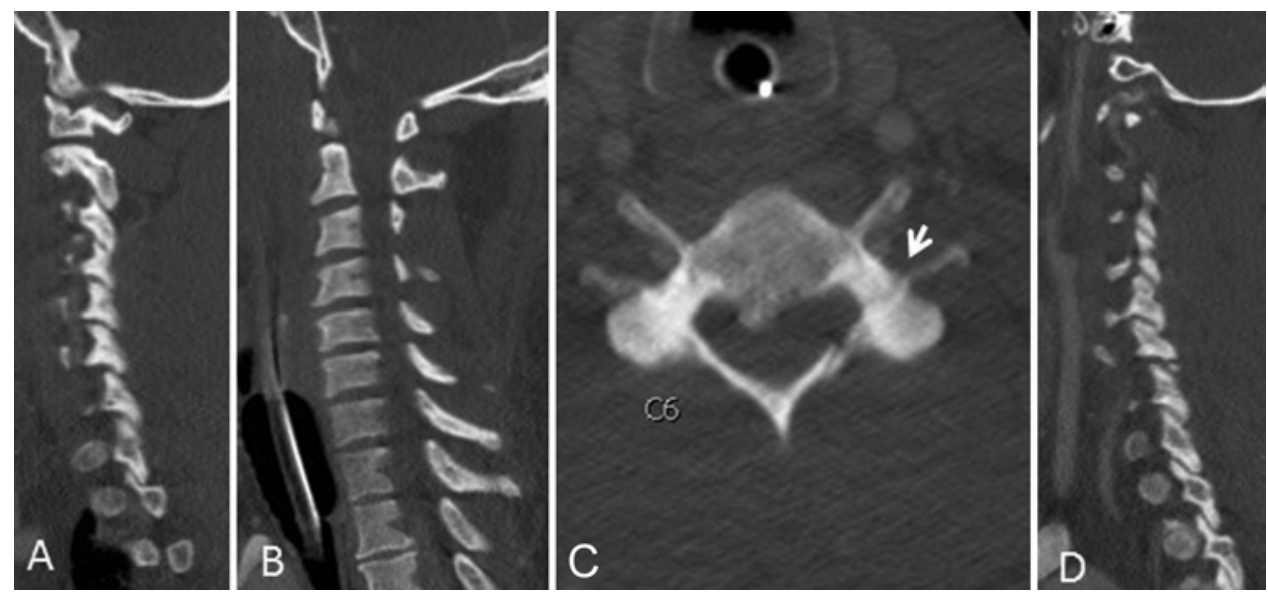

FIG. 4. Sagittal (A, B, and D) and axial (C) CT scans of a cervical spine belonging to a 41-year-old female patient who was admitted to the trauma center following a motor vehicle accident. Her GCS score was 7 (motor score 5) and her motor examination was not testable. The CT scans indicate a floating lateral mass of C-6 on the left side (arrow). This patient had an SLIC score of 2 and an instability score of 4.8. She was first treated with a hard collar, but this treatment failed and she required internal fixation from the front.

The mean instability score was $3.2 \pm 1.5$ (surgery group 3.6, nonoperative group 3.0; Table 1).

\section{Surgical Versus Nonoperative Management}

Of the 25 patients, $15(60 \%)$ were treated using an orthosis (Miami J hard collar in 12 patients and a halo vest in 3 patients) and $10(40 \%)$ by internal fixation. Selection of surgical versus nonoperative management of patients with facet fractures was conducted using a consensus reached solely by the patient and his or her surgeon after a full description of risks and benefits of each management strategy. The patient was told that while surgery was successful in preventing dislocation over time and possibly relieving radicular pain and paresthesias, nevertheless, an operative intervention had its defined risks. The risks of surgery were described as difficulty with swallowing, hoarseness, and infection. In addition, surgery could cause nerve root damage and predispose a patient to adjacent segment and construct failure. Alternatively, nonoperative management under close observation with biweekly CT scans of the cervical spine to rule out subluxation had a $60 \%$ chance of success for natural fusion of the broken facets. There was a close to $40 \%$ chance of subluxation over time with nonoperative management, which carried the potential for nerve root or spinal cord injury if dislocation was missed. The choice of external fixation using either a hard collar or halo was made by the patients or their families after a full description of risks and benefits of each device. Internal fixation was accomplished using anterior cervical discectomy and fusion $(n=8)$ or short-segment posterior fusion with foraminotomy $(\mathrm{n}=$ 2). An anterior versus posterior cervical spine approach for internal fixation, with or without foraminotomy, was an option that was chosen by the patient's surgeon upon discussion with the patient. Patients were followed-up for a mean of 12.1 months (range 3-60 months).

\section{Treatment Failure}

The ultimate determination of a failed nonoperative approach was based on progressive translation or kyphosis over time. More than 3 millimeters of translation or $11^{\circ}$ of kyphosis during follow-up was considered unsafe to continue nonoperative management. Almost none of the patients with unsuccessful conservative management based on imaging studies had new evidence of root or spinal cord injury.

\section{Statistical Analysis}

The Fisher's exact test was used to compare the proportion of failures between the surgery and nonsurgery groups. To compare mean values of age, instability score, and SLIC score between patients who had solid fusion and those who had subluxation over time, we used the Student t-test (for normally distributed variables) or Mann-Whitney U-test (for nonnormally distributed variables). The statistical program Stata SE (version 12.1, StataCorp LP) was used for analysis.

\section{Results}

\section{Surgical Group}

Of the 25 patients, 10 (40\%) chose to undergo internal fixation of their facet fractures shortly after admission (mean 2.3 days). None of these patients experienced construct failure; however, upon routine clinic follow-up, 1 patient $(10 \%)$ was noted to have both angulation and translation at the level below the motion segment with facet fracture, which had solid fixation (Table 2). This patient did not experience pain, sensory symptoms, or weakness indicating spinal cord or radicular compression.

\section{Nonoperative Group}

Fifteen patients with isolated nondisplaced or minimally displaced facet fractures were managed using an orthosis (12 patients with a Miami J hard collar and 3 with halo vest external fixation). External fixation failed in 9 patients $(60 \%$; Table 2) by exhibiting subluxation (mean $3.67 \pm 0.66 \mathrm{~mm}$ ). In addition, 1 patient developed 
B. Aarabi et al.

TABLE 1: Characteristics of 25 patients with isolated nondisplaced unilateral subaxial facet fractures

\begin{tabular}{|c|c|c|c|}
\hline Variable & All Patients (\%) & No Surgery (\%) & Surgery $(\%)$ \\
\hline no. of patients & $25(100)$ & $15(60)$ & $10(40)$ \\
\hline male sex & $19(76.0)$ & $12(80.0)$ & $7(70.0)$ \\
\hline mean age $\pm S D$ (yrs) & $38.5 \pm 15.5$ & $35.4 \pm 18.2$ & $43.1 \pm 9.0$ \\
\hline \multicolumn{4}{|l|}{ mechanism of injury } \\
\hline motor vehicle accident & $18(72.0)$ & $11(73.4)$ & $7(70.0)$ \\
\hline fall & $3(12.0)$ & $2(13.3)$ & $1(10.0)$ \\
\hline other & $4(16.0)$ & $2(13.3)$ & $2(20.0)$ \\
\hline mean admission ASIA motor score \pm SD & $99.2 \pm 1.6$ & $99.1 \pm 1.9$ & $99.4 \pm 0.8$ \\
\hline \multicolumn{4}{|l|}{ injury severity } \\
\hline \multicolumn{4}{|l|}{ Allen mechanistic classification } \\
\hline compressive-extension Stage 1 & $22(88.0)$ & $14(93.3)$ & $8(80.0)$ \\
\hline distractive-extension Stage 1 & $2(8.0)$ & $0(0.0)$ & $2(20.0)$ \\
\hline distractive-flexion Stage 1 & $1(4.5)$ & $1(6.7)$ & $0(0.0)$ \\
\hline mean SLIC severity score \pm SD & $3.0 \pm 1.2$ & $2.3 \pm 1$ & $3.5 \pm 1.2$ \\
\hline mean instability score \pm SD & $3.2 \pm 1.5$ & $3.0 \pm 1.8^{*}$ & $3.6 \pm 1^{*}$ \\
\hline \multicolumn{4}{|l|}{ segmental level of injury } \\
\hline C-3 & $1(4.5)$ & $1(6.6)$ & $0(0.0)$ \\
\hline C-4 & $0(0.0)$ & $0(0.0)$ & $0(0.0)$ \\
\hline C-5 & $0(0.0)$ & $0(0.0)$ & $0(0.0)$ \\
\hline C-6 & $7(28.0)$ & $4(26.7)$ & $3(30.0)$ \\
\hline C-7 & $17(68.0)$ & $10(66.7)$ & $7(70.0)$ \\
\hline $\mathrm{T}-1$ & $0(0.0)$ & $0(0.0)$ & $0(0.0)$ \\
\hline \multicolumn{4}{|l|}{ lateral mass fracture morphology } \\
\hline sagittal plane & $12(48.0)$ & $7(46.6)$ & $5(50.0)$ \\
\hline axial plane & $8(32.0)$ & $5(33.3)$ & $3(30.0)$ \\
\hline coronal plane & $3(12.0)$ & $2(13.3)$ & $1(10.0)$ \\
\hline floating lateral mass & $2(8.0)$ & $1(6.8)$ & $1(10.0)$ \\
\hline follow-up (mos) & 12.1 & 13.8 & 9.9 \\
\hline
\end{tabular}

* One data point missing.

kyphotic deformity (Cobb angle $25.6^{\circ}$ ). These patients required realignment and internal fixation by discectomy and fusion after a mean of $38.4 \pm 33.7$ days after injury (range 5-103 days).

\section{Illustrative Case}

After a motor vehicle crash, this 25-year-old woman was admitted to the Shock Trauma Center with neck pain and numbness of her right index and middle fingers. Her GCS score was 15 and American Spinal Injury Association (ASIA) motor score was 100. A CT scan of her cervical spine revealed an axial fracture of the lateral mass of $\mathrm{C}-7$ on the right side (Fig. $5 \mathrm{~A}-\mathrm{C}$ ). Magnetic resonance imaging did not reveal evidence of spinal cord signal change; however, the instability score was rated at 4.8 . The SLIC score was calculated as 3 . This patient received nonsurgical management and was sent home with an or-

TABLE 2: Comparison of risk factors for failure of natural fusion in 25 patients with isolated nondisplaced subaxial facet fractures

\begin{tabular}{lcccc}
\hline \multicolumn{1}{c}{ Variable } & $\mathrm{N}$ & Failed Fusion & Solid Fusion & $p$ Value \\
\hline mean age \pm SD & 25 & $26.9 \pm 6.6$ & $46.2 \pm 14.9$ & 0.0008 \\
mean instability score \pm SD & 22 & $4.6 \pm 2.6$ & $4.4 \pm 1.6$ & 0.8836 \\
mean SLIC score \pm SD & 24 & $2.6 \pm 1.1$ & $3.4 \pm 1.2$ & 0.1293 \\
surgery & & & 9 & 0.018 \\
yes & 10 & 1 & 6 & \\
no & 15 & 9 & & \\
\hline
\end{tabular}



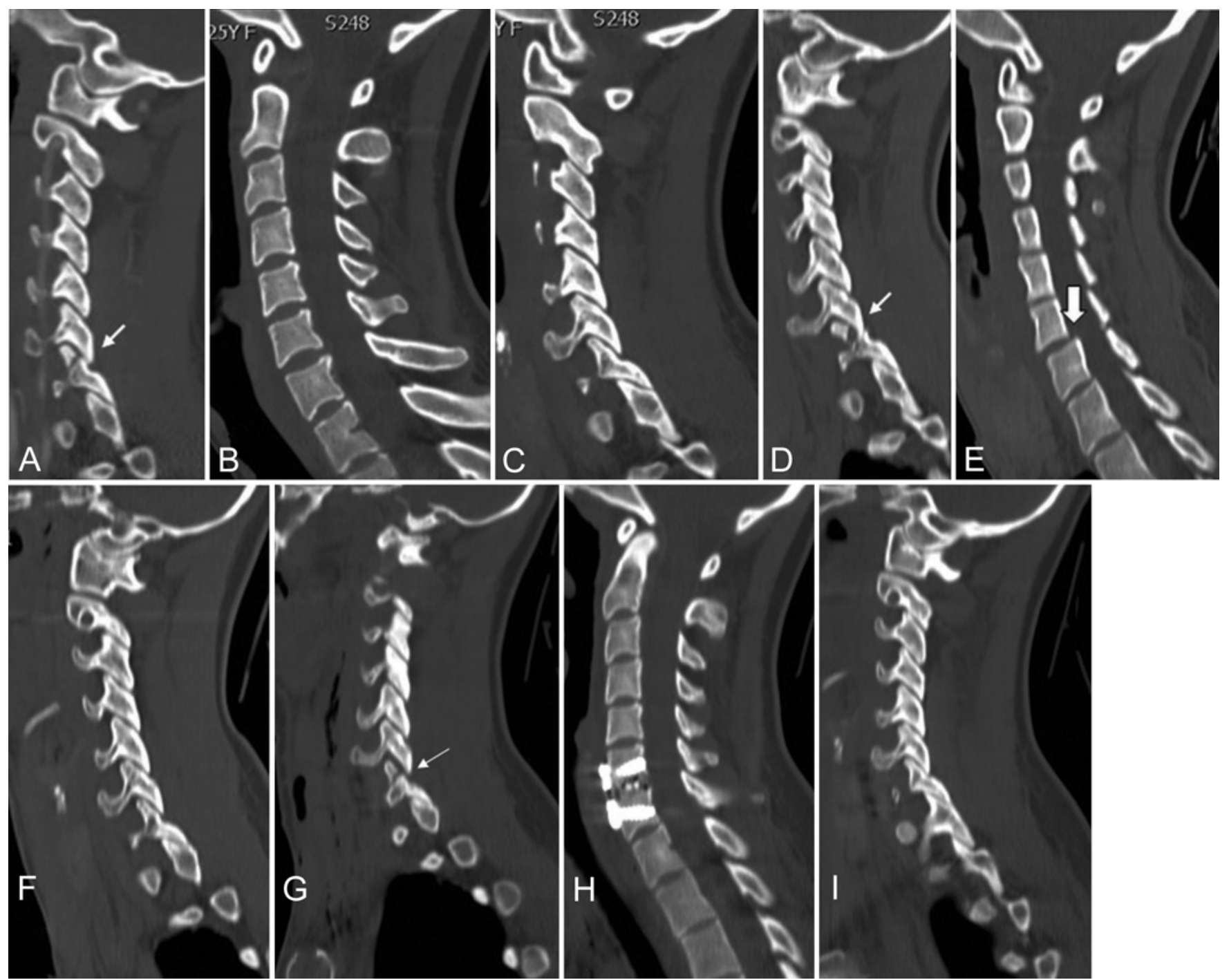

FIG. 5. Sagittal CT scans obtained in the patient described in the illustrative case. A-C: Admission reconstructed views reveal an axial fracture of the lateral mass of C-7 on the right side (arrow). D-F: Images obtained from a return to the clinic 23 days after injury showing evidence of rotational subluxation (3.2-mm translation; arrows). G-I: Postoperative images obtained after open reduction and internal fixation of new and progressive subluxation (arrow).

thosis (Miami J hard collar). During the period the patient was followed-up in the clinic, CT revealed evidence of rotational subluxation (3.2-mm translation; Fig. 5D-F) 23 days after discharge, even in the absence of further neurological deficit. In July 2007 the patient underwent open reduction and internal fixation via an anterior approach. She remained symptom-free 1 year after her accident (Fig. 5G-I).

\section{Discussion}

In this study of patients with unilateral nondisplaced subaxial facet fractures, we compared multiple demographic, clinical, injury severity, and anatomical characteristics of the surgical and nonoperative cohorts (Table 1) looking for major differences predisposing to instability. Younger patients were more prominent in the nonoperative group, which we believe represents a selection bias ( $\mathrm{p}=0.07$, Wilcoxon rank-sum test). Of significance was the fact that isolated nondisplaced or minimally displaced facet fractures did not follow the usual criteria for instability. Also, surgery was a definitive management strategy that was significantly superior to orthosis in preventing rotational subluxation over time and loss of alignment ( $p$ $=0.018$, Table 2).

Nonoperative management failed in almost twothirds of the 15 patients in this study who had isolated nondisplaced or minimally displaced subaxial cervical spine lateral mass/facet fractures; these fractures required realignment 5-103 days later by internal fixation. The argument is that if the instability criteria of White and Panjabi, Anderson et al., and Vaccaro et al. apply here, then rotational instability under physiological load with an orthosis is counterintuitive., , $20-22^{2}$

Our findings confirm the experiences of Lifeso and Colucci, Spector et al., and Lee and Sung. ${ }^{12,13,19}$ In a combined retrospective and prospective study, Lifeso and Colucci ${ }^{13}$ evaluated the fusion rate of isolated nondisplaced 
facet fractures in 50 patients. The fractures in $21(42 \%)$ of 50 patients who were treated using an orthosis uniformly failed to fuse and had to be corrected by surgical means. When the fractures in the study were treated by surgical intervention, the investigators had a better success rate in securing long-term stability using anterior cervical discectomy and fusion than using internal fixation by the posterior approach. In 2006, Spector et al. ${ }^{19}$ investigated the morphology of isolated unilateral facet fractures and tried to correlate the morphology with the degree of instability. In this study, management was unsuccessful in 5 $(21 \%)$ of 24 patients who were treated nonoperatively, and these patients required open reduction and internal fixation. Intact facet joints resist forward subluxation of motion segments. ${ }^{23}$ In the study by Lee and Sung, ${ }^{12}$ nonoperative management of isolated nondisplaced lateral mass or facet fractures carried an $80 \%$ risk of failure. In their cohort of 39 patients, orthotic treatment failed in 12 of 15 patients with isolated facet fractures, and these patients underwent surgical correction.

In their cadaveric studies, Zdeblick et al. (1993), Cusick et al. (1988), and Raynor et al. (1985) discovered that resection of $50 \%-75 \%$ of subaxial facet joints in conjunction with their capsules increased compressive load in flexion and extension, decreased torsional stiffness of motion segments, and increased flexion sprain and shear, collectively facilitating unopposed translation..$^{5,16,23}$

The extent of in vivo facet injury and its relationship with loss of alignment over time was studied by Spector and colleagues. 19 These investigators' findings indicated that if the craniocaudal height of the fractured facet fragment was more than $40 \%$ of the height of the intact contralateral lateral mass, or if the fragment had an absolute height of more than $10 \mathrm{~mm}$, there was a significant risk for failed nonoperative management. We were not able to follow the methodology of these investigators. In our in-depth review of axial, coronal, and sagittal reformatted views of the cervical spine in our 25 patients, we discovered that lateral mass fractures were quite variable in morphology. The lateral mass fracture line was sagittal in 12 patients, axial in 8, and coronal in 3 (Table 1); in addition, a floating lateral mass was noted in another 2 patients (Figs. 1-4). Comparison of the fracture morphology between the surgical and nonoperative groups did not reveal any major statistical differences.

In 1997, Halliday et al..$^{8}$ studied 2 groups of patients with nondisplaced or minimally displaced facet fractures without spinal cord injury. There were 12 patients in each category. One group responded to an orthosis, and the other required internal fixation because of progressive subluxation. Following MRI evaluation, the investigators analyzed the anatomical integrity of 4 components of the discoligamentous complex to define stability against physiological loads. These components were the anterior longitudinal ligament, posterior longitudinal ligament, facet capsule, and interspinous ligament. These researchers concluded that surgical intervention was indicated if 3 of 4 ligaments were defective after trauma. ${ }^{8}$ In our study, we attempted a detailed analysis of 7 components of the discoligamentous complex in the anterior and posterior elements of the involved motion segment (see above). In the entire cohort the mean instability score was 3.2 (range 1-5.7) with no difference between the surgical and the nonoperative groups.

Three articles in $2007^{7,11,15}$ indicated the greater benefit of surgical intervention compared with nonoperative management of isolated nondisplaced facet fractures. Rabb et al. were uniformly successful in managing unilateral isolated facet fractures with internal fixation by an anterior approach. ${ }^{15}$ Kwon et al., ${ }^{11}$ in a prospective randomized controlled trial, compared anterior and posterior surgical management of facet injuries. In their study, 34 of 42 patients with facet fractures and no spinal cord injuries were managed either by anterior or posterior spinal fusions. The fusion rate was similar in both groups and surgical intervention was uniformly successful. ${ }^{11}$ In a multicenter retrospective study by Dvorak and colleagues, ${ }^{7}$ patient-reported outcomes in 90 patients with facet injuries were investigated. In this study the mean 36-Item Short Form Health Survey Physical Component Summary score of the operative patients with follow-up longer than 18 months was 6.7 points higher than the mean of the nonoperative patients ( $p$ $=0.017$ ). In this investigation 72 patients were treated surgically and 18 nonoperatively. In addition, conservatively managed isolated facet fractures caused significantly more bodily pain and functional disability than surgical management. $^{7}$

\section{Conclusions}

In this ambispective study, nonoperative management of isolated nondisplaced or minimally displaced subaxial facet fractures produced a $60 \%$ failure rate, which was significantly inferior to surgical intervention. None of the conventional demographic, clinical, imaging, or injury severity variables, morphology classifications, and instability checklists could predict failure rate and long-term subluxation. Although a randomized or prospective observational study can shed new light on the issue of instability of isolated nondisplaced subaxial facet fractures, we perceive these fractures to be unpredictable during natural behavior under physiological loads, with no clear predictive risk factors for gradual translation over time. As such, nonoperative management must be complemented with interval imaging studies until solid fusion is confirmed by CT or flexion/extension views on radiography. It is not unreasonable if, in preferred cases, surgical intervention is chosen as a primary modality of management.

\section{Disclosure}

Dr. Vaccaro has direct stock ownership in Advanced Spinal Intellectual Properties, Bonovo Orthopaedics, Computational Biodynamics, Cross Current, Cytonics, Electrocore, Flagship Surgical, FlowPharma, Gamma Spine, Globus, In Vivo, Innovative Surgical Design, K-2 Medical, Location Based Intelligence, NeuCore, Paradigm Spine, Progressive Spinal Technologies, R.S.I., Replication Medica, Rothman Institute and Related Properties, Small Bone Innovations, Spine Medica, Spinicity, Spinology, Stout Medical, and Syndicom; is an employee of the Rothman Institute; serves as a consultant to the Gerson Lehrman Group, Guidepoint Global, Innovative Surgical Design, Medacorp, and Stout Medical; has received royalties from Aesculap, Biomet Spine, DePuy, Globus, Medtronics, 


\section{Management of unilateral nondisplaced subaxial facet fractures}

NuVasive, and Stryker Spine; serves on Boards and Committees for AO Spine, Association of Collaborative Spine Research, Innovative Surgical Design, and Spinicity; and has received grants from Cerapedics, NuVasive, and Stryker Spine.

Author contributions to the study and manuscript preparation include the following. Conception and design: Aarabi, Vaccaro. Acquisition of data: Aarabi, Mirvis, Shanmuganathan, Holmes. Analysis and interpretation of data: Aarabi, Akhtar-Danesh. Drafting the article: Aarabi. Critically revising the article: all authors. Reviewed submitted version of manuscript: all authors. Approved the final version of the manuscript on behalf of all authors: Aarabi. Statistical analysis: Akhtar-Danesh. Administrative/technical/material support: Aarabi. Study supervision: Aarabi.

\section{References}

1. Allen BL Jr, Ferguson RL, Lehmann TR, O'Brien RP: A mechanistic classification of closed, indirect fractures and dislocations of the lower cervical spine. Spine (Phila Pa 1976) 7:1-27, 1982

2. Anderson PA, Moore TA, Davis KW, Molinari RW, Resnick DK, Vaccaro AR, et al: Cervical spine injury severity score. Assessment of reliability. J Bone Joint Surg Am 89:1057-1065, 2007

3. Beyer CA, Cabanela ME, Berquist TH: Unilateral facet dislocations and fracture-dislocations of the cervical spine. J Bone Joint Surg Br 73:977-981, 1991

4. Bucholz RD, Cheung KC: Halo vest versus spinal fusion for cervical injury: evidence from an outcome study. J Neurosurg 70:884-892, 1989

5. Cusick JF, Yoganandan N, Pintar F, Myklebust J, Hussain H: Biomechanics of cervical spine facetectomy and fixation techniques. Spine (Phila Pa 1976) 13:808-812, 1988

6. Denis F: The three column spine and its significance in the classification of acute thoracolumbar spinal injuries. Spine (Phila Pa 1976) 8:817-831, 1983

7. Dvorak MF, Fisher CG, Aarabi B, Harris MB, Hurbert RJ, Rampersaud YR, et al: Clinical outcomes of 90 isolated unilateral facet fractures, subluxations, and dislocations treated surgically and nonoperatively. Spine (Phila Pa 1976) 32:30073013, 2007

8. Halliday AL, Henderson BR, Hart BL, Benzel EC: The management of unilateral lateral mass/facet fractures of the subaxial cervical spine: the use of magnetic resonance imaging to predict instability. Spine (Phila Pa 1976) 22:2614-2621, 1997

9. Harris JH Jr, Edeiken-Monroe B, Kopaniky DR: A practical classification of acute cervical spine injuries. Orthop Clin North Am 17:15-30, 1986

10. Holdsworth F: Fractures, common dislocations, fractures-dislocations of the spine. J Bone Joint Surg Br 45:6-26, 1963

11. Kwon BK, Fisher CG, Boyd MC, Cobb J, Jebson H, Noonan
$\mathrm{V}$, et al: A prospective randomized controlled trial of anterior compared with posterior stabilization for unilateral facet injuries of the cervical spine. J Neurosurg Spine 7:1-12, 2007

12. Lee SH, Sung JK: Unilateral lateral mass-facet fractures with rotational instability: new classification and a review of 39 cases treated conservatively and with single segment anterior fusion. J Trauma 66:758-767, 2009

13. Lifeso RM, Colucci MA: Anterior fusion for rotationally unstable cervical spine fractures. Spine (Phila Pa 1976) 25:20282034, 2000

14. Nicoll EA: Fractures of the dorso-lumbar spine. J Bone Joint Surg Br 31B:376-394, 1949

15. Rabb CH, Lopez J, Beauchamp K, Witt P, Bolles G, Dwyer A: Unilateral cervical facet fractures with subluxation: injury patterns and treatment. J Spinal Disord Tech 20:416-422, 2007

16. Raynor RB, Pugh J, Shapiro I: Cervical facetectomy and its effect on spine strength. J Neurosurg 63:278-282, 1985

17. Schaefer DM, Flanders AE, Osterholm JL, Northrup BE: Prognostic significance of magnetic resonance imaging in the acute phase of cervical spine injury. J Neurosurg 76:218-223, 1992

18. Shapiro SA: Management of unilateral locked facet of the cervical spine. Neurosurgery 33:832-837, 1993

19. Spector LR, Kim DH, Affonso J, Albert TJ, Hilibrand AS, Vaccaro AR: Use of computed tomography to predict failure of nonoperative treatment of unilateral facet fractures of the cervical spine. Spine (Phila Pa 1976) 31:2827-2835, 2006

20. Vaccaro AR, Hulbert RJ, Patel AA, Fisher C, Dvorak M, Lehman RA Jr, et al: The subaxial cervical spine injury classification system: a novel approach to recognize the importance of morphology, neurology, and integrity of the disco-ligamentous complex. Spine (Phila Pa 1976) 32:2365-2374, 2007

21. White AA, Southwick WO, Panjabi MM: Clinical instability in the lower cervical spine: a review of past and current concepts. Spine (Phila Pa 1976) 1:15-27, 1976

22. White AA III, Panjabi MM (eds): Physical properties and functional biomechanics of the spine, in: Clinical Biomechanics of the Spine, ed 2. Philadelphia: Lippincott Williams \& Wilkins, 1990, pp 1-83

23. Zdeblick TA, Abitbol JJ, Kunz DN, McCabe RP, Garfin S: Cervical stability after sequential capsule resection. Spine (Phila Pa 1976) 18:2005-2008, 1993

Manuscript submitted August 1, 2013.

Accepted November 25, 2013.

Please include this information when citing this paper: published online January 3, 2014; DOI: 10.3171/2013.11.SPINE13733.

Address correspondence to: Bizhan Aarabi, M.D., F.R.C.S.C., Department of Neurosurgery, University of Maryland School of Medicine, 22 S. Greene St., Ste. S-12-D, Baltimore, MD 21201. email: baarabi@smail.umaryland.edu. 